\title{
Illustrations' Functions in Typical English Dictionaries of English Idioms
}

\author{
Zeng, Xiaoguang*
}

School of Foreign Languages, Quanzhou Normal University, Quanzhou City, Fujian Province, PRC

xgz123@qztc.edu.cn

Keywords: illustration, idiom, dictionary

Abstract. The illustration (illustrative examples) is an important part of an English dictionary of English Idioms. It has very important functions, which are discussed in detail in this paper with illustrations from some typical classical English dictionaries of English idioms.

\section{Introduction}

The illustration (illustrative examples) is an important part of a dictionary. Its importance is more clearly seen in an English Dictionary of English Idioms (EDEI), which is heavily culture-bound. The quality of the illustrations is a major index of the quality of an EDEI, for the illustrations provide on the syntactic level, a direct, concrete display of the pragmatic behaviors of English idioms, which is what readers of an EDEI expects of. To illustrate the functions of EDEI, the author chooses some illustrations from such typical classical EDEIs as Longman Dictionary of English Idioms (LDEI), Longman Dictionary of Phrasal Verbs (LDPV), Oxford Dictionary of Current Idiomatic English. Vol. 1 \& Vol. 2. (ODCIE), American Idioms and Useful Phrases (AIUP) and Webster's Third New International Dictionary of English. (1st ed.) (W3). In specific, the functions of the illustrations in the EDEI can be classified into following aspects.

\section{Functions of Illustrations in Typical English Dictionaries of English}

2.1 To evidence the existence of the new idiom or the existence of the new meaning of an idiom 2.1.1 To evidence the existence of the new idiom. Every idiom is generated in a certain context when the speaker can find no other existing expression but his own idiomatic coinage. It can exist orally or in written form. In the English idiomatic dictionary, it is the written form that evidences the existence of an idiom, for we cannot record sounds directly in the dictionary but indirectly in their written form. For this reason, the most convincing evidence to support the existence of the idiomatic neologisms is found in the illustrations.

go through the roof (to rise exorbitantly, usually said of price)

The phrase can't be found in LDEI, LDPV or ODCIE, but it can be found in AIUP:

go through the roof.../ The tickets, which retail for $\$ 12.50$, were fetching as much as $\$ 50$ a piece yesterday. But scalpers said that weekend prices are higher and holiday-time prices will go through the roof. (New York Post Nov. 25, 1992)

2.1.2 To evidence the existence of the new meaning of an established or old idiom

Established or old idioms may have new meanings. This is the other side of idiomatic neologism. In the same way, illustrations from written or spoken texts can evidence the existence of the new meaning, e.g. 'get out':

ODCIE (1975) ---

get out ${ }^{1}$ become known, leak.; get out $\mathbf{t}^{\mathbf{2}}$ receive, draw, be given. get out ${ }^{\mathbf{3}}$ speak, utter.

get out ${ }^{4}$ (cricket) (cause to) lose one's wicket; be dismissed, dismiss.

get out ${ }^{5}$ succeed in solving, or finding the correct answer to; work out 3

LDVP (1983) ---

It has not only the above senses but also several new ones. All are supported with illustrations.

2. to remove (something): I can't get this nail out, it's too tight.

3. to (cause to) descend from a vehicle: How many passengers got out at the last stop?

4. to clean or remove (a mark, dirt, etc.): This special cleaning liquid should get that spot of oil out 
(of the cloth).

5. to bring (something) out from a place where it is stored or hidden: I'll get some clean sheets out for you. I do hate having to get the sewing machine out every time I want to make a dress. Will you get the car out while I get the children ready? The thief got out a gun and forced the owner to give him the jewels.

6. to take (something such as money or a book) from a place where it is officially kept: The library will only allow you to get six books out at a time. I shall have to go to the bank again and get some more money out.

*13. to print or publish (something such as a book): How long does it take each day to get the newspaper out? Tom hopes to get his new book out before the end of the year. We try to get the magazine out as often as possible.

*14. to prepare and deliver (something written or spoken): We should be able to get out our plans in another week. I have to go and work, I must get out my next speech. We get the magazine out to our customers by post.

*17. to make (someone) stop working because of disagreement: If we get all the workers out, we may be able to force the government to act.

*18. to cause (someone) to be on duty: We've got police out all over the area, looking for the missing girl. Sorry to get you out at this late hour, doctor, but Mother became suddenly ill in the middle of the night.

baker's dozen

In ODCIE and LDEI (and other EDEIs I can find), the meaning of the idiom is 'thirteen'. But in W3 it has a new meaning: '2: a small unspecified number'. An illustration is used to evidence the meaning: <very few persons were there, and only a baker's dozen showed any real interest>

2.2 As a sort of defining device to exemplify or illustrate the meaning of the idiom defined so the meaning of the idiom becomes more concrete and convincing. The key to the meaning of a lexical unit (a single word or idiom) is frequently to be found in the syntactic context. To determine the meaning of any lexical unit, one must inevitably look to the context. Similarly, the well-designed illustrative examples in a DEI can surely help the learners strengthen their understanding of the meaning of the entry idioms because the illustrations can, indeed, play the role of the context here.

2.2.1 To illustrate or exemplify the meaning

come down ${ }^{1}$ [A1 emph] collapse; drop; fall

$\square$ I took out just one screw and the whole thing came down.

$\square$ The snow came down thick and fast.

come down ${ }^{3}$ [A1 emph] fall, be reduced

$\square$ Prices are much more likely to go up than to come down.

[The illustrations in come down ${ }^{1}$ and come down ${ }^{3}$ can clearly show their meanings respectively and especially the difference between the same explanatory word 'fall' in both entries.]

2.2.2 To illustrate or exemplify the meaning of the transformation of an idiom not clearly defined.

the lights are going out all over Europe (catchphrase)

$\square$ Folk-memory, let alone contemporary history, has attributed to Edward Grey one memorable phrase.

On the morning war broke out in 1914, the Foreign Secretary looked out of his office window and

noticed the gas-lights of London being extinguished. He observed, with a touch of that melancholy which marked him increasingly as he approached old age, that the lights were going out all over Europe and would not be lit again in his lifetime. L

$※ \square(\mathrm{NONCE})$ (reader's letter) Listen to our lady of the green ink (obscure reference), Clivo, alivo, and remember her when the lights go out all over your European culture circus. You could do worse, artistically, than the 'Sydney Bulletin'. L

$※ \square($ NONCE) These were the years when the big circuses disappeared. Chipperfields decamped for South Africa, Bertram Mills, the greatest circus of all, dissolved itself. The coloured bulbs had gone out all over Britain. RT

$※ \square$ Marcel Boulesten was the first TV Chef in the world. In the early pre-war days of television, he was a great success. When the lights went on again, Boulesten was dead: but the BBC were still 
not convinced that an Englishman could do the job. L

[The four illustrations clearly show the meanings of the idiom. The second to the fourth clearly show the meanings of its transformations whose meanings are not clearly given by the definition.]

2.2.3 Help to distinguish the idiomatic meanings of an idiom from less idiomatic ones

(1) bread and butter ${ }^{1}[n+n$ non-rev] slices of bread spread with butter (esp as part of an ordinary English meal eg breakfast or tea)

$\square$ Finally, stuffed with ham, cake, bread and butter, and pints of dark tea, they moved from the table. HD

$\square$ After that I cut bread and butter and then washed up the mugs and saucepans and cleaned the kitchen. UTN

(2) bread and butter ${ }^{2}$ [ $n+n$ non-rev] one's ordinary means of livelihood, esp. at a very basic level and without any extras

口TERRY: Do you back horses? JACK: Do we? Do we! JERRY: They're our bread and butter, kid. YAA

$\square$ The 'different matters' which concern students (in Sweden) today are bread-and-butter ones ---jobs and the Government loans they live on. OBS

$\square$ 'Dear Pyle', I wrote and was tempted for the only time to write 'Dear Alden' (his Christian name), for after all this was a bread-and-butter letter of some importance and it differed little from other bread-and-butter letters in containing a falsehood. QA

$\square$ attrib use bread and butter matters, and esp a bread and butter letter = 'a letter written as a conventional way of thanking sb for hospitality or some other kindness'.

(3) bread and butter ${ }^{3}[n+n$ non-rev] simple and wholesome; without extraordinary features or frills

$\square$ I wish often that I could have fixed my life at that moment --- the car rolling smoothly down the narrow street, that wonderful bread-and-butter smell coming from the open spaces nearby --- and inside the car the masculinity of steel and oil and warm leather. RATT

$\square$ 'She always seemed a bit insipid to me,' Bob said, 'strictly the bread and butter Miss.' RATT

[The illustrations in (1) illustrate the headphrase's less idiomatic meaning, while the illustrations in

(2) and (3) illustrate the headphrase's more idiomatic meanings.]

2.2.4 To indicate the meaning which is not included in the definition (but in the footnote).

all things to all men [Comp (NP)] (saying) (adopt, modify, one's behaviour, one's actions etc.) in a way one thinks will be acceptable to the person, or persons, one is with (either in a genuine attempt to please or just to be ingratiating)

...

$\square$ She was all things to all men and spent most of her life being so, because the men outnumbered the girls at Ford by four to one. RFW

$\square$ ambiguous play on expression in the last example, suggesting sexual availability.

2.2.5 To illustrate the change of meaning of an idiom

2.2.5.1 Decrease of meaning (The publication of ODCIE (vol. 2) is later than LDEI)

at large

[LDEI] 1. free; not bound or in prison: 'Essex county police are still searching in vain for the madman who is at large in the deadly marshes of the coastal region.' (Tom Stoppard)

2. in general; as a whole: ...the quality which distinguishes them as a group from the public at large. (New Statesman 22 Nov 74) $\|$ I have no doubt that it was public opinion in the United States and in the world at large that finally ended the Vietnam war. (The Listener 31 Oct 74)

3. old-fash freely; without limits: he gave out presents at large

[ODCIE (Vol. 2)] generally; as a unit; as a whole

$\square$ That humanity at large will ever be able to dispense with artificial Paradises seems very unlikely. DOP

$\square$ Too wrapped up in his indignation to notice that Ned was there, he simply addressed the company at large. TC 
'Opportunity to do just what?' 'Why, to dig in and find some facts and reveal them to the country at large,' cried Dogson. HD

[Sense 1 and 3 in LDEI are omitted in ODCIE.]

2.2.5.2 Increase of meaning (The publication of LDPV is later than ODCIE (vol. 1))

award to

[ODCIE (Vol. 1)] give; grant officially (to)

$\square$ The first prize was awarded to the youngest competitor.

$\square £ 12000$ was the amount that the court awarded (to the victim of the accident).

[LDPV] 1 to give (something such as a prize or money) officially to (someone): [T1+to] The Councillor has been invited here today to award the school prizes to our successful boys and girls. \$50,000 has been awarded to the university for a study of the effect of art on the ways in which children learn.

2 to give (something) by a decision in a court of law to (usu. someone): [T1+to] The judge awarded a large sum of money to those hurt by the explosion.

[Sense 2, which is not recorded in ODCIE (Vol. 1) is newly added into LDPV.]

2.2.5.3 Replacement of meaning

argue the toss

[LDEI] not $\mathrm{fml}$ to oppose or argue with a decision that has already been taken and that cannot be changed: there's nothing to be gained by arguing the toss---you'll just have to accept that the job's been given to someone else. [v]

[ODCIE (Vol. 2)] disagree about sth; discuss a matter of dispute

$\square$ A letter was sent to the then Minister for Industry. It did not argue the toss over his ruling. It simply asked for a meeting with him to discuss the matter. NS

$\square$ Time is pressing. If we delay while the toss is being argued in London and Washington, the operation will never be launched in July. MFM

$\square$ He thought we might have shown less of his face. Maybe he was right. Anyway, I argued the toss a bit and finally he said keep it in. PP

[The replacement of meanings of certain entries is clearly seen in the headphrases above.]

\subsection{To illustrate the pragmatic behaviors of the idiom defined}

(All the following illustrations, except for that in 2.3.2.1.3.7, are taken from ODCIE.)

2.3.1 Analysis made from the perspective of the relationships between the illustrations and the pragmatic codes in every individual entry

2.3.1.1 In the entry without any pragmatic codes provided.

run amok

$\square$ (headline) Man Runs Amok on Railway. The two-and-a-half hour drama began at London Bridge station when a man was challenged for his ticket. He attacked the collector, then assaulted three other men. OBS

$\square$ As the mediamen run amok in this quiet backwater, literally millions of ordinary hard-working people will be forced to pay $6 p$ every day to subsidise their so-called activities. $G$

$\square$ Teddy Roosevelt was the first man of his time who saw clearly that America was no longer a rural nation, but an industrial giant run amok. $\mathrm{L}$

[The use of 'run amok' as a predicate and an attributive is clearly displayed by the illustrations.]

2.3.1.2 In the entry where the pragmatic behaviors of the headphrase have been indicated by its pragmatic codes

after hours $[\mathrm{A}($ PrepP) $]$ after the normal, or (legally) permitted, period of time for doing sth has finished $\mathbf{V}$ : open, remain open; serve sb

$\square$ Look, you know as well as I do that I'd lose my licence if I served you drink after hours.

$\square$ After-hours drinking is common in some country districts.

$\square$ Though interest in the new share issue had been high during the day, few after-hours dealings were reported.

$\square$ attrib use after-hours drinking, dealings.

['serve sb' in the collocation code and 'after-hours' in the footnote are illustrated in the main 
illustration body.]

2.3.1.3 In the entry where the pragmatic behaviors of the headphrase are not all covered by the pragmatic code

airs and graces [ $n+n$ non-rev] affected manners intended to give an impression of fastidious refinement (but producing an opposite effect on the observer) V: give oneself; be full of

$\square$ She's kind-hearted enough once you get behind all her airs and graces.

$\square$ I don't think much of her son---he's so conceited and as full of airs and graces as a young lord.

$\square$ (NONCE) The Contessa, the Renata who had billions of lire, a castle here, a villa there, a grand apartment in Milan, was a pal, no airs, only graces. YWT

$\square$ always pl.

[Additional transformation information 'no airs, only graces' is provided in the last illustration.]

all agog [Comp (AdjP)] eager and full of excited anticipation S: he, they, we, I; the crowd, the children V: $\Delta$ be, seem;

leave sb. A: for him (to appear), for the results (to come through); to see him

$\square$ I was all agog to see again the three-mile long beach of Traigh Swish on whose glittering white sands...RM

$\square$ The children were all agog for the show to begin and for Santa Claus to appear.

$\square$ They hung about, looking down the street, returned into the bookshop and then came out again and waited all agog. UTN

[Additional v-collocation behavior 'wait all agog' is provided in the last illustration.]

2.3.2 Analysis made from the perspective of the two prominent pragmatic features of English idioms

2.3.2.1 To illustrate the transformation of the headphrase in the EDEI

2.3.2.1.1 Replacements or substitutions in the EDEI

2.3.2.1.1.1 Non-variation \& variation in number: (1) Non-variation in number (2) Variation in number

sb's bark is worse than his bite (1)

$\square$ There are a number of 'spicy', 'off the shoulder' periodicals, or sex-and-bittiness weeklies and monthlies, whose bark is in an illuminating way much worse than their bite. UL

a stuffed shirt (2)

$\square$ But these aren't big people at all, Yves. These are frightfully, frightfully, unimportant people. They're what are called stuffed shirts, Yves. ASA

2.3.2.1.1.2 Non-variation \& variation in tense: (1) Non-variation in tense (2) Variation in tense we shall see what we shall see (1)

$\square$ Now I see what the trouble is. Ah well, as for the civil servants that's not so serious, and as for the liaison, well we shall see what we shall see. TBC

$\square$ 'Dick's going to give up smoking.' 'That wouldn't be a bad idea. We shall see what we shall see, however.'

crime doesn't pay (2)

$\square$ He (the chief of police) was a lank and scowling man, whose polished boots and belt proclaimed his importance; he had only recently taken over this post, and it was obvious that he intended to prove to the inhabitants that crime did not pay. DF

$\square$ Last month Mr Feather (a union leader) urged employers to adopt a firm line in resisting unofficial pressure---if they do not, he warned, they would be demonstrating that 'crime pays.'

2.3.2.1.1.3 Replacements or substitutions of the component in the idiom

all boys etc together

$\square$ I didn't know, until I asked Robert later, that it was the caretaker (Robert called him the 'concierge', to show that we were all cosmopolitans together. $\mathrm{CON}$

the thin red line

$\square$ (source) The Russians dash on towards that thin red streak topped with a line of steel. BRITISH EXPEDITION TO THE CRIMEA (W H RUSSELL 1820-1907)

jam tomorrow

$\checkmark$ There are other sharply observed characters, notably Peter's rich Belgravia parents, father a fascist- 
minded brigadier, mother a White Queen with thoughts of jam yesterday.

\subsection{Addition in EDEI}

\section{fly high}

$\square$ One only hoped that in SW1 (a fashionable London district) they weren't going to find themselves socially too far out of their depth. We must all, even nations, learn not to fly too high; or come to that, too fast. NS

\section{at a tender age}

$\square$ Bonnie Langford, at the tender age of $\mathbf{1 2}$ has already formulated her views on possible stardom. TVT

\section{airs and graces}

$\square$ (NONCE) The Contessa, the Renata who had billions of lire, a castle here, a villa there, a grand apartment in Milan, was a pal, no airs, only graces. YWT

\subsection{Permutation in the EDEI}

\subsection{Nominalization}

\section{fly high}

$\square$ When the implications of the new (examination) system become clear, it is just possible that one or two education boards (which are technically independent of the government) may go it alone and preserve O-level as an elite examination for high-flyers. NS

\section{all clear}

$\square$ One of his few memories of the war was sitting in dank and dark air-raid shelters waiting for the wail of sirens to sound the All-clear.

$\square$ With both the unions and management actively in support, the Government may now feel it has the all-clear to tackle the problems facing British industry.

\subsection{Adjectivization}

\section{a blind alley}

$\square$ But remember, when you're fully qualified you'll earn three times as much as him and have a fair amount of job satisfaction while he'll be going from one blind-alley job to another.

\section{across the board}

$\square$ Each insurance agent can tell you about his own company's policies. For across-the-board comparative advice, it is still best to go to an insurance broker. ST

(as) sweet as honey

$\square$ Grow these honey-sweet melons in your own garden!

no room to swing a cat

$\square$ (NONCE) The crucial defect of this government's white paper was that it proposed to draw boundary lines tightly around the built-up areas of the conurbations, leaving them no breathing, no catswinging, no developable space. NS

\subsection{Gerundization}

\section{(as) poor as a church mouse}

$\square$ Being poor as church mice is all very well when you're young, but Sam is nearly thirty now and ought to be looking for a better job.

(as) sweet as honey

$\square$ If you don't like the Browns then don't visit them. If you go on being sweeter than honey every time they telephone, of course they'll keep inviting you.

\section{attack is the best form of defence}

$\square$ The best form of defence being attack he rose from his bed next day and rode down to the beach where the Customs flag was flying over the hulk, and the Preventive Officers were patrolling. ARG no room to swing a cat

$\square$ (NONCE) For example, sets had rarely been used before in (Studio) Pres B and getting them up there was a bit like swinging a cat in a coal cellar. RT

\subsection{Infinitivization}

\section{the weather breaks / holds}

$\square$ Youngsters enjoy this snowy weather. Ours are praying for it to hold till the weekend so that they 
can go sledging.

\subsection{Passivization}

\section{argue the toss}

$\square$ Time is pressing. If we delay while the toss is being argued in London and Washington, the operation will never be launched in July. MFM

\section{no room to swing a cat}

$\square$ (NONCE) Cats do not get swung too much in Japan and by the same token the man who wants to swing a golf club has his problems. OBS

\subsection{Reversal}

\section{at one time or another}

$\square$ He has indeed at one or another time argued both for and against most of the big changes in Turkey over the past thirty years. OBS

\subsection{Sententialization}

\section{LDEI (1979)---}

\section{a peg on which to hang}

...: they arrived at the meeting with their own ideas, and any peg would do to hang them on.

\subsection{Deletion in the EDEI}

wave a (magic) wand (and do sth)

$\square$ 'National security' is a magic wand which tends to anaesthetise opposition---and those entrusted with waving it have a power more menacing than can be found in any statute. NS

2.3.2.2 To illustrate the collocability of the headphrase in the EDEI

hell for leather [A (NP)] (informal) with the greatest possible energy and speed V: run, ride, drive, work, go (at sb / sth)

$\square$ We've started them all right. A whole lot of mad March hares streaking hell for leather across the open country. ARG

$\square$ 'Do nightingales sing all day?' 'All day, all night,' Pop said, 'Like everything else in the mating season, they go hell for leather.' DBM

$\square$ For some reason, absence of information often goes hand in hand with hell for leather expansion. OBS

$\square$ She wrote the first draft in one hell for leather month. OBS

$\square$ end position, attrib use hell-for- leather expansion, a hell-for-leather hurry.

[The illustrations in the entry show that 'hell for leather' can serve as an adverbial phrase following a verb and as an adjectival phrase before a noun.]

2.4 To illustrate the stylistic value of the headphrase in the entry

make answer / reply [V + O] (formal) answer; reply

$\square$ 'What did you do before?' she asked. 'I was a student of history,' I made answer. PP

$\square$ He presented an Address from the House of Commons to which Her Majesty was graciously pleased to make reply.

[The stylistic value 'formal' is clearly illustrated in the second illustration.]

2.5 To give the learners some notions of the foreign culture. English idioms are culture-bound.

They themselves are one important aspect of English Culture.

The English etc dearly love a lord

$\square \mathrm{Mr}$ worsthorne holds that the common people defer to birth but not to mere position: they dearly love a lord but they can't stand a bureaucrat. $L$

[This illustration shows mainly the political attitude of the British people.]

an Englishman's home is his castle

$\square$ Jack clearly enjoys his home and his privacy. 'The old bit about an Englishman's home being his castle fits me to a T.'

[This illustration shows mainly the British people's attitude towards private life.]

ladies first

$\square$ And then Mr. Collins pulled open the doors from inside the Hall ---and the noise seemed to be switched off. 'Now,' he said, 'Ladies first--- let yours come on in please, Miss Elliot.' TT 
[This illustration shows mainly the British people's attitude towards the relationship between male and female.]

\section{Conclusion:}

Without the illustrations, an English Dictionary of English Idioms is not a EDEI in the full sense but only a glossary, a skeleton without flesh. In fact, all the pragmatic behaviors of an English idiom are demonstrated through its illustrations (text fragments in which its role is appropriately played).

\section{References:}

[1] American Idioms and Useful Phrases. The Commercial Press International Co., Ltd., 1995.

[2] Longman Dictionary of English Idioms. Longman Group Limited, Hawlow and London, 1979.

[3] Longman Dictionary of Phrasal Verbs. Longman Group Limited, Longman House, Burnt Mill, Harlow, 1983.

[4] Oxford Dictionary of Current Idiomatic English. Vol. 1 \& Vol. 2. Oxford University Press, Oxford, $1975,1983$.

[5] Webster's Third New International Dictionary of English. (1st ed.). Philip Bobcock Gove. G. \& C. Merriam co. Publishers, Springfield, Massachusetts, U.S.A. 1963.

[6] Chitra Fernando, Idioms and Idiomaticity. Shanghai Foreign Language Education Press, 2000. 